\title{
An atmospheric approach to the city-psychosis nexus. Perspectives for researching embodied urban experiences of people diagnosed with schizophrenia
}

Une approche atmosphérique de la relation ville-psychose. Perspectives pour étudier les expériences vécues en milieu urbain par les personnes diagnostiquées schizophrènes

Marc Winz

\section{(2) OpenEdition}

\section{Journals}

\section{Electronic version}

URL: http://journals.openedition.org/ambiances/1163

DOI: $10.4000 /$ ambiances. 1163

ISSN: 2266-839X

\section{Publisher:}

Direction Générale des Patrimoines - DAPA - MCC, UMR 1563 - Ambiances Architectures Urbanités $(\mathrm{AAU})$

\section{Electronic reference}

Marc Winz, «An atmospheric approach to the city-psychosis nexus. Perspectives for researching embodied urban experiences of people diagnosed with schizophrenia », Ambiances [Online], Varia, Online since 08 June 2018, connection on 19 April 2019. URL : http://journals.openedition.org/ ambiances/1163; DOI : 10.4000/ambiances. 1163

This text was automatically generated on 19 April 2019

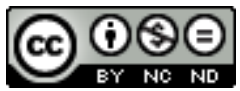

Ambiances is licensed under a Creative Commons Attribution-NonCommercial-NoDerivatives 4.0 International License. 


\title{
An atmospheric approach to the city-psychosis nexus. Perspectives for researching embodied urban experiences of people diagnosed with schizophrenia
}

\author{
Une approche atmosphérique de la relation ville-psychose. Perspectives pour \\ étudier les expériences vécues en milieu urbain par les personnes diagnostiquées \\ schizophrènes
}

\section{Marc Winz}

1 The relationship between cities and psychosis, notably reported in 1939 by Robert Faris and Warren Dunham, has gained renewed interest in recent years, and urbanicity - as labelled within psychiatry - has been found to be associated with increased risk for schizophrenia and psychosis (Vassos, Pedersen, Murray et al., 2012, p. 1118). However, the mechanisms linking urban milieus and mental illness are still unknown. In medical research, most studies addressing the relation between urbanicity and psychosis or schizophrenia have dealt with the city as substance, "as set of material things and social characteristics" (Söderström, Abrahamyan Empson, Codeluppi et al., 2016, p. 109) to which one would be exposed, rather than the city as experience. In order to gain insight in the ways in which urbanicity and psychosis are entangled, Söderström, Abrahamyan Empson, Codeluppi et al. argue that this static perspective is not sufficient; there is a need to shift to a more fluid one, where the "city is approached as a flow of experience, in which patients encounter elements that are assembled in various ways depending on how they see and practice 'the urban"' (p. 109).

2 The aim of this paper is to ground such an analysis in a theoretical framework built on the notions of affective atmosphere, as conceptualized in recent Anglo-Saxon human geography and on the notion of ambiance, as conceptualized in research on architecture 
and urban studies in France. These two literatures have coexisted until pretty recently, with only very little confrontation. Besides, the two concepts are often used interchangeably, as synonyms, both within their respective linguistic contexts, as well as across linguistic frontiers. Although those concepts are very close theoretically (Adey, Brayer, Masson et al., 2013; Thibaud, 2015; Jones \& Jam, 2016), slight variations between them can be identified. In doing so, we keep in mind, as Jones and Jam note, not "to draw artificial distinction between the concepts of atmospheres and ambiances" (Jones \& Jam, 2016, p. 318).

3 The article is structured as follows. Drawing upon the confrontation of those concepts, the paper first highlights the similarities of ambiance and affective atmospheres, before underlining their differences. It is argued that ambiance and affective atmosphere share a common spatial perspective, while stressing two different registers of experience: whereas ambiance puts emphasis on a perceptual, sensory and conscious level of experience of urban environment, affective atmosphere stresses a more pre-reflective, bodily dimension. Following that, the paper discusses the heuristic value of this shared spatial perspective for investigating the city-psychosis nexus; providing particularly fertile conceptual ground from which to capture urban experience as lived by people diagnosed with schizophrenia, this atmospheric approach points dimensions not sufficiently taken into account in research in psychopathology. Finally, in the last section, the papers sketches out a methodological framework in coherence with these conceptual considerations.

\section{Ambiance and affective atmospheres, a common shared spatial perspective}

4 This section first briefly sheds light on the definition of both ambiance and affective atmosphere, in order to subsequently depict five main similarities between the concepts identified in this paper. Firstly, ambiance and affective atmospheres convene a multisensorial register of perception. Secondly, they emerge in the coalescence of object and subject. Thirdly, they are never static, but instead evolving constantly. Furthermore, affective atmosphere and ambiance are situated, and hence multiple within a city. Finally, they comprise a performative dimension. As a foreword, we may say that both concepts largely integrate their respective common sense meaning and a part of the "intuitively obvious", on top of which layers of interpretation and theorization have been accumulated (Jones \& Jam, 2016, p. 318).

5 Ambiance has a long tradition in French research. Its origins lay in the work of philosopher and urban socio-anthropologist Jean-François Augoyard and stems from work on urban walking and the sensory dimensions associated with it: sound and sound effect within cities were of central interest in Augoyard's work (Augoyard \& Torgue, 1995). Until today, ambiance is still particularly associated with the literature produced by scholars of the Centre de Recherche sur l'Espace Sonore et l'environnement urbain (CRESSON), founded by Augoyard in 1979 and based in the school of architecture in Grenoble (École nationale supérieure d'architecture de Grenoble). Embedded within a school of architecture, the notion was then primarily used to describe objectively measurable features of architectural environment, such as acoustic, thermic and lighting for example. Over time, the notion became more complex and interdisciplinary, including 
not only the configuration created through the manipulation of those features, but also the way those situations were experienced, hence "articulating built forms, sensible forms and social forms" (Thibaud, 2015, p. 40). Jean-Paul Thibaud, one of the leading scholars working on and theorizing ambiances, defines the notion as follows:

To put it in a nutshell, an ambiance can be provisionally defined as a space-time qualified from a sensory perspective. It appears as an alternative to bridge the sensitive, the spatial and the social domains. (Thibaud, 2011a, p. 203)

6 The provisional trait given to this definition by Thibaud is recurrent in the literature on ambiance. Scholars working on ambiance often refuse to define the concept, Amphoux speaking rather of an "indefinition" than a definition of ambiance (2003, p. 53). Generally speaking, ambiance involves the built and material dimension of inhabited space, as well as the sensory and subjective experience - the lived experience (Thibaud, 2011b, p. 43) of architecture and urban design. The manipulation or the staging of an ambiance, which refers to the "active interventions with the intention of re-engineering the feeling of urban spaces" (Jones \& Jam, 2016, p. 317) is very present in the French theorization of the notion, and central in the origins of the notion of ambiance within architecture ${ }^{1}$.

Whereas research on ambiance is strongly based on practice, as well as oriented towards practical research outputs, literature on affective atmospheres is more theoretically driven (Jones \& Jam, 2016, p. 318). As a matter of fact, the origins of the concept of atmosphere, on which that of affective atmosphere is elaborated, lie in the work of the German philosopher Gernot Böhme. In an article published in 1993, Böhme proposes the concept of atmosphere to be at the foundation of a new aesthetics, understood as theory or philosophy of perception. Therefore, Böhme's understanding of atmospheres is resolutely phenomenological: "on entering a room one can feel oneself enveloped by a friendly atmosphere or caught up by a tense atmosphere" (1993, p. 113). His account of atmospheres laid the foundations of an ever since growing field of research, both in the Anglo-American context - discussed in the present paper - and in the German-speaking context. Within German human geography, Böhme's phenomenological interpretation of atmospheres has notably been taken up by Jürgen Hasse (2012), who has been a key researcher in bringing the discipline - and especially urban studies - towards the investigation of atmospheres. Although it could be of interest to consider this third major trend in the field, it is beyond the scope of this paper to do so.

Within recent Anglo-American human geography, Ben Anderson draws on Böhme and conceptualizes atmospheres alongside affect in a seminal paper entitled Affective Atmosphere, as "a kind of indeterminate affective 'excess' through which intensive spacetimes can be created" (Anderson, 2009, p. 80).

Affective atmospheres are a class of experience that occur before and alongside the formation of subjectivity, across human and non-human materialities, and inbetween subject/object distinctions (after Seigworth, 2003, see Anderson and Wylie, 2009). As such, atmospheres are the shared ground from which subjective states and their attendant feelings and emotions emerge. (Anderson, 2009, p. 78, emphasis in original text)

9 The few scholars confronting the two notions (Adey, Brayer, Masson et al., 2013; Thibaud, 2015; Jones \& Jam, 2016) agree on the fact that those two different research traditions meet "on the basis of the same area of questioning" (Thibaud, 2015, p. 40), in "an adjustment of thinking towards and around the relations between bodies and their environments" (Adey, Brayer, Masson et al., 2013, p. 301). To put it simply, scholars "working on both atmospheres and ambiances are concerned, among other things, with 
how places feel" (Jones \& Jam, 2016, p. 317). It is generally considered that both affective atmospheres as well as ambiances do not exist as substances. They require a perceiving subject. Sensory perception and experience are therefore crucial to both research traditions (Bille, Bjerregaard \& Sørensen, 2015, p. 32). If in early works sound and sound effects were of particular interest to researchers on ambiance, other senses have been given more attention since. Nowadays, the concept of ambiance is one that stresses the multisensorial dimension of perception: "[...] any ambiance involves all the senses at once (hearing, seeing, smelling, touching, tasting, moving...) and relies on a multisensorial experience" (Thibaud, 2011a, p. 204). While this aspect is explicitly and extensively addressed in the literature on ambiance, it is less discussed in literature on affective atmosphere, where it is rather taken for granted. Nevertheless, ambiances and affective atmosphere do not solely depend on sensory perception; they are considered to emerge neither entirely from the social and physical environments one encounters, nor entirely from one's personal or collective subjective experience. Scholars on both ambiance (Amphoux, 2003; Thomas \& Thibaud, 2004; Chadoin, 2010; Thibaud, 2011a; 2011b; 2012; 2013; 2015; Kazig \& Masson, 2015) and atmosphere, respectively affective atmospheres (Böhme, 1993; Anderson, 2009; Adey, Brayer, Masson et al., 2013; Buser, 2014; Duff, 2015; Bille, Bjerregaard \& Sørensen, 2015) argue that these notions question the binary distinction of object and subject. Affective atmospheres as well as ambiances are considered to be "in the middle" (Buser, 2014), being "neither fully subjective nor fully objective but circulate in an interstitial place in and between the two" (Adey, Brayer, Masson et al. 2013, p. 301).

10 This relational nature of affective atmospheres and ambiances leads to two other common attributes. First, emerging in the coalescence of bodies (both material and human), affective atmosphere and ambiance are never fixed, but "constantly in a state of becoming" (Buser, 2014), and therefore subject to change. Second, emerging partially from environmental bodies in presence, affective atmospheres and ambiances are situated and plural: city dwellers experience several different atmospheres and ambiances when moving around the city. Finally, scholars on both affective atmospheres (Anderson, 2009; Bissell, 2010) and ambiance (Thibaud, 2016) acknowledge their performative nature. Accordingly, they are considered as potentially inhibiting or disinhibiting actions and/or emotions:

Possibly the most effective way of grasping the idea of an affective atmosphere is therefore to think of it as a propensity: a pull or a charge that might emerge in a particular space which might (or might not) generate particular events and actions, feelings and emotions. (Bissel, 2010, p. 273)

What does an ambiance do? One wonders here what the ambiance makes it possible to perceive, to do, to live, to share. In terms of experience, ambiance has the capacity to suggest movements, incite behaviors, induce affects, activate the memory of the body, reinforce sociabilities. (Thibaud, 2016, p. 694, emphasis in original text) ${ }^{2}$

11 The common ground of these concepts discussed so far, the "clear overlaps between ideas around ambiances and atmosphere" (Jones \& Jam, 2016, p. 318), provide a shared atmospheric - spatial perspective summarized by Buser as follows:

From this spatial perspective, we can imagine how in daily experience, one might experience any number of affective atmospheres - coalescing and collapsing, erupting and dissipating along with shifting relationships and movements between bodies and objects. (Buser, 2014, p. 234) 
12 Buser writes on affective atmospheres, but as shown, his statement is accurate for ambiance as well. This spatial perspective is crucial if we seek to capture the urban experience as suggested by Söderström, Abrahamyan Empson, Codeluppi et al. (2016) in the introduction of this paper. Despite this common perspective, slight variations between the two concepts can be identified, which render problematic the transition from one to another, argue Kazig \& Masson (2015, p. 217). The following section discusses those nuances and suggests taking advantage of them for an empirical investigation of how people diagnosed with schizophrenia experience cities, instead of considering them problematic.

\section{Different registers of experience}

13 According to Thibaud, ambiance and atmosphere highlight different aspects of the subject-object relationship (Thibaud, 2015, p. 40). In this section, the article suggests to further investigate those different aspects. It will be argued that ambiance and affective atmosphere allow capturing two different registers of experience; while ambiance stresses a sensory and consciously mediated experience, affective atmosphere points to an embodied, pre-reflective register.

14 Affect and emotions gained new interest in social sciences with the "affective turn", which came with a wide range of interpretations of the notions of affect and emotion, as well as of the way these two are linked. Affect and emotion are sometimes used as synonyms, although definitions of each of these categories are widely discussed, and vary across disciplines and theories. In The Affect Theory Reader, published in 2010, Melissa Gregg and Gregory J. Seigworth compile contributions from different authors, in order to tentatively lay out no less than eight different orientations in the theorization of affect $(2010$, p. 6). Within recent human geography, the discussion on affective atmosphere is enshrined in a debate differentiating affect from feeling or sensation, as well as from emotion. In order to establish this distinction, cultural geographer Ben Anderson draws on Massumi who's understanding of affect comprises three core ideas, summarized by Wetherell (2012, p. 61) as follows: (i) affect is non-conscious, and (ii) it moves in a chronological sequence from body response to consciousness and cognition; thus, affect could be neatly separated from body/brain responses. Finally, (iii) Massumi considers body/brain responses to be autonomous, and beyond representation ${ }^{3}$.

While Massumi separates the body from mind, Ben Anderson "tries to stitch [them] back together" (Wetherell, 2012, p. 66) in suggesting a three-layer cake model of the relationship between affect, feeling and emotion. On the first, deepest layer, is affect itself, in Massumi's understanding; affect is inscribed in the non-cognitive, unconscious, corporeal/bodily and immediate register. It is both beyond pre-cognition and cognition. In this conception, affect is considered to be diffuse: "affect refers to flows (of affect) between bodies" (Pile, 2010, p. 9, referring to Anderson). The second layer is considered to be pre-reflective, pre-cognitive; feelings or sensations remain tacit and intuitive and are not yet expressed or named. Finally, the last level is that of cognition, where we find emotions: "emotions are expressed feelings, being both conscious and expressed" (Pile, 2010, p. 9). They refer to a reflexive moment, to the actual awareness and verbalization of the sensation (Massumi, in Labyiani) or to "the socio-cultural expression of [a] felt intensity" according to McCormack (2008, p. 414). 
16 Hence, in this conception it is considered that the differences between affect, feelings and emotion lie at the level of consciousness at which they occur: "[a]ffect, sensation and emotion thus occupy different points on a continuum going from body to mind, each having a different temporality ${ }^{4}$ " (Labanyi, 2010, p. 224). As such, affect always lies outside of representation: either it is outside of consciousness and therefore not able to be put in linguistic representation, or it is no more affect, but has become emotion. Obviously, "this creates a bit of an epistemological impasse for empirical investigation" (Ellis, Tucker \& Harper, 2013, p. 725). However, Derek P. McCormack argues that the concept of affective atmosphere can be understood in its affective sense as "something distributed yet palpable, a quality of environmental immersion that registers in and through sensing bodies while also remaining diffuse, in the air, ethereal" (McCormack, 2008, p. 413). The idea of a registration of affect in bodies is also present in Massumi's understanding, as he qualifies affect as intensities, which can be registered in the physiology of human bodies, and measured through heart rate fluctuation or respiratory system activity (Massumi, 2002). Wetherell argues that Anderson "seems to include autonomic bodily responses registering that something affecting has happened such as the heat of a blush, the tension of an angry body, and so on" (Wetherell, 2012, p. 66) at the second level of his layer cake model. Besides, Brennan, who is interested in how affect circulate, considers the transmission of affect as being of atmospheric nature, with social or psychological origins, and physiological or biological implications:

In other words, the transmission of affect, if only for an instant, alters the biochemistry and neurology of the subject. The "atmosphere" or the environment literally gets into the individual. (Brennan, 2004, p. 1)

If affect is ineffable and outside of representation, its registration in sensing bodies seems to be graspable. Ellis, Tucker and Harper call this registration of affective activity a "third realm" (2013, p. 725), between that of unconsciousness and that of discursive representation. Because of the theorization of atmospheres alongside with affect in recent human geography, affective atmosphere are concerned with the deeper layer of experience, from which feelings and emotions emerge. Affective atmospheres take into consideration the unconscious and pre-reflective part of experience. In this conception, the body, or rather the register of affective bodily experience (not yet mediated through consciousness), comes to the foreground. In contrast, this level of experience is rather absent in the concept of ambiance. This is not to say that literature on ambiance totally evacuates pre-subjectivity. In the more recent literature and research, Thibaud introduces the notion of affective tonalities (tonalités affectives) as a constitutive part of an ambiance, in order to grasp and include a subconscious layer of experience:

The moment of the constitutive sensing of aesthetic experience refers rather to ways of experiencing the world, relates to affective tones and ways of being together in an environment. With such an aesthetics of ambiance, we have to deal with the pre-reflective dimension of the experience, the one that goes first and foremost through a bodily experience and an immediate sensation ${ }^{5}$. (Thibaud, 2013, p. 8)

18 Affective tonalities are considered by Thibaud to be pre-reflexive in a phenomenological perspective. In other words, they can be considered as conscious, but not reflected upon. As such, affective tonalities might refer to the feelings and sensation described above, and less to the level of affect. Besides, this aspect remains rather marginal in the literature on ambiance, whereas it is much more central in the conceptualization of the notion of affective atmosphere. Moreover, affective tonalities are not very well defined; as a result, 
it is sometimes used to refer to the valence of the feeling one might associate with an ambiance. Hence, within French research, ambiance is much more focused on perception (Adey, Brayer, Masson et al., 2013, p. 302) and "tends to emphasize more the situated, the built and the social dimensions of sensory experience" (Thibaud, 2015, p. 40).

In summary, it has been shown that - perhaps due to its background within architecture as note Jones and Jam (2016) - ambiance is much more concerned with the consciously lived experience, paying particular attention to the sensory register and the materiality of the environment. Affective atmospheres, on the other hand, take into consideration the pre-cognitive and the bodily part of that experience. This is not to say that authors writing on affective atmospheres are exclusively interested in that part of experience, evacuating other dimensions, but that they stress this dimension more than the ambiance approach. Together, these two concepts focus the research on both how the urban is lived and experienced through our senses and in relation to social and material environments, and how it literally gets under our skin - on a less conscious level.

\section{Ambiance, affective atmosphere and urban mental health}

20 Why relate the concepts of affective atmosphere and ambiance to the mental health-city nexus? In this section, the article depicts how geographical research on urban mental health can be enriched when approached through this atmospheric lens. I first draw a brief state of the art of the literature on urban mental health, before outlining how ambiance and affective atmosphere have been used within mental health research. This leads, thirdly, to pinpointing three key areas of relevance where ambiance and affective atmosphere provide a particularly distinctive and productive perspective: inter-sensorial perception, transitions between atmospheres or ambiances, a focus on the built environment.

21 Within psychiatry, the vulnerability-stress model (also called diathesis-stress model), first introduced by Zublin and Spring in 1977, unites different approaches to psychosis and provides a useful framework for understanding onset and relapse of psychoses (Zublin \& Spring, 1977). Widely accepted today, this model posits that the onset of the illness results from the interaction between constitutional factors of vulnerability and external stress factors. Vulnerability marks a threshold of tolerance, which, once exceeded, leads to psychotic decompensation. Among the external stress factors, living in urban areas has been seriously considered as a risk factor since the early 2000s. Therefore, for two decades, a growing number of studies have confirmed the higher prevalence of schizophrenia in the city (Mortensen, 2000; Allardyce et al., 2001; Van Os, 2004). Consequently, the correlation between urbanity and schizophrenia is now verified (Kelly et al., 2010; Krabbendam \& Van Os, 2005) and a meta-analysis of recent studies shows a rate of people with schizophrenic disorders 2.37 times higher in the city (Vassos, Pedersen, Murray et al., 2012, p. 1118). However, the nature of the link that binds them, as well as the mechanisms involved still remain very unclear (Söderström, Abrahamyan Empson, Codeluppi et al., 2016, p. 104).

"Urban stress" has been advanced as a plausible hypothesis relating psychosis to cities. But this notion of "urban stress" remains however rather diffuse and unclear (Abbott, 2012), "referring to a wide spectrum of potential factors, ranging from exposure to noise 
and pollution to more complex concepts such as social interaction" (Söderström, Abrahamyan Empson, Codeluppi et al., 2016, p. 105). It is therefore important to clarify this notion, to refine our understanding of how a particular environment can be stressful, and if possible identify "which parts of a busy city life are the most stressful" (Abbott, 2012, p. 164). In a nutshell, we may say that stress is identified as aversive for psychosis, and so is urbanicity. And life in cities is considered stressful, but at the same time, "urban stress" remains vague. According to the Vulnerability-stress model, psychotic crises occur in the encounter between predispositions present within the person in question, and life events or environmental influences perceived and experienced as a source of stress. It is important to note that minor stress events - and especially their accumulation - have been identified as crucial in the etiology of psychoses within the vulnerabilitystress model:

Rather than reactions to the extreme exposures that life events often represent, sensitivity to minor life events or daily hassles has been postulated to more closely resemble the underlying vulnerability for psychopathology, especially in schizophrenia. (Myin-Germeys, Peeters, Havermans et al., 2003, p. 124)

It is therefore crucial, argue Söderström, Abrahamyan Empson, Codeluppi et al. (2016), to investigate how different factors of stress combine in the experience of cities, and moreover, how they are seen and experienced from an emic point of view. The question now is: where do ambiance and atmosphere, and, more specifically, the nuance between them discussed in this paper, lead us in relation to conceptualizing and investigating the city/psychosis nexus?

Tracing the common history of psychiatry and ambiance as conceptualized by Thibaud, psychiatrists Chaperot and Altobelli (2014) show that ambiances have principally been apprehended through their effects on psychotic (schizophrenic and borderline) patients in institutional milieus. The authors conclude that ambiance "is a fundamental element in the treatment of psychiatric patients, which must be considered with more attention that is generally given to it" (p. 542). Regarding affective atmosphere, medical anthropologist Cameron Duff draws from the geographical literature on affective atmosphere "to prise open the spatial and embodied rhythms of recovery" (Duff, 2015, p. 2), in order to research the ways socio-spatial factors are entangled in the process of recovery. Therefore, on the one hand, ambiance is considered to be of importance in relation to psychiatry, but has been studied only in institutional and not in urban contexts, and, on the other hand, affective atmosphere has been explored in the everyday experience of recovery of patients, but not in relation to stressful and aversive events, and with no regard to the different levels of experience the two concepts refer to.

In the following, the article pinpoints three key areas where the shared spatial perspective - the atmospheric approach outlined above - provides a particularly productive angle for studying the city/psychosis nexus, with regard to minor stress events and their accumulation. First, these concepts both propose to consider the five senses together in the perception of the environment, and as well as in its analysis, rather than separately. This approach encourages us to focus on the multi- or inter-sensorial perception of the city: in other words, we need to take into account the fact that we see, feel, touch and hear the city at the same time and we need to look at how our five senses work together, simultaneously and/or consecutively (Candau, 2010) in the constitution of urban experience and in the creation of stress feelings. Attention disorders, or more precisely the difficulty in filtering relevant information is often present in people 
diagnosed with schizophrenia (Nevid, Rathus, Greene et al., 2009, p. 259), and patients may also experience hypervigilance, defined as increased attention to sensory stimuli (Nevid, Rathus, Greene et al., 2009, p. 261). Söderström, Abrahamyan Empson, Codeluppi et al. (2016) have already highlighted the importance of sensory stimulation and its potential source of discomfort in the experience of urban space by people diagnosed with schizophrenia. Taking into account the inter-sensorial perception of the environment should help to hone our understanding of the sensory overload, known in psychiatry as an excessive number of stimuli surpassing a patient's ability to absorb them (Bunney, Hetrick, Bunney et al., 1999).

Second, affective atmospheres and ambiances are situated, since they are co-constructed by the bodies (human and non-human) in presence. As a result, urban affective atmospheres and ambiances are multiple on the one hand, and volatile on the other hand. When approached through the atmospheric lens, cities are understood as producing "a flow of experiences in which patients encounter elements that are assembled in various ways depending on how they see and practice 'the urban' " (Söderström, Abrahamyan Empson, Codeluppi et al., 2016, p. 109). Hence, studying the urban experience through an atmospheric perspective requires paying attention to the transitional moments, the moments of passage and switching between different affective atmospheres and ambiances. Above all, it is a question of how patients experience these transitions. Those changes become particularly relevant when keeping in mind that the question of adaptation to new situations is a daily difficulty for people living with this diagnosis (Lysaker \& Lysaker, 2008). From this point of view, the question then arises: what if the problem was not so much an ambiance or an affective atmosphere as such, but rather the transitions, the succession and sequencing of them, the alternation between aversive and pleasant ambiances and affective atmospheres, their permanent instability and unpredictable transitions?

Thirdly, an atmospheric approach of the relationship between individuals and the urban environment makes it possible to include a fundamental and often forgotten part of this space when it comes to the study of the effect of urban environment on mental health: its physical dimension. Golembiewski sees the absence of the physical component in epidemiology or etiology notably in the fact that the physical hypothesis contradicts an axiom rooted in modern medicine and its conception of mental health, namely "the assumption that the brain is a cognition machine and mental illness is a fault in the machinery, not the input (the phenomenological environment)" (Golembiewski, 2017). Integrating the material dimension stems particularly from the ambiental perspective as developed at CRESSON, where architectural features are of central importance. This is to ask the question of the role of the built city, of materiality, in the experience of urban space by people with mental disorders. According to Golembiewski, the physical environment and architecture, omnipresent in the urban environment, represent as much information and stimuli to be dealt with by city dwellers, and " $t]$ his is where the built environment may become psychotoxic" (Golembiewski, 2017).

From an "urban stress" perspective, the notion of atmosphere opens the door to an integrative and multidimensional approach from an emic perspective. Such an approach should contribute to a deeper understanding of what in urban life can be experienced as a source of stress and discomfort, or the opposite as an environment of well-being and comfort. As showed, an atmospheric approach should help honing how questions around inter-sensorial perception, transition between ambiances and the built environment 
impact on micro-stress experiences of patients. The two registers of experience described by ambiance on the one hand and affective atmosphere on the other provide the conceptual framework for researching the impact of urbanicity on individuals diagnosed with schizophrenia through an innovative methodological apparatus, aiming to map people's embodied reaction to urban environment.

\section{Methodological perspectives} affective atmosphere leads inevitably to an in situ approach, where situations and experience of those situations are necessarily studied hic et nunc. An atmospheric approach, be it through ambiance or affective atmosphere, is based on an immersion in the surrounding world. Thematizing experience in this perspective leads to portray what it is like to be immersed in an environment (Thibaud, 2013, p. 6). Not only is an in situ method inherent to an atmospheric approach, it is also necessary for a more fine-grained understanding of the city-psychosis nexus. According to Myin-Germeys, Oosrchodt, Collip et al. (2009), daily life experience has been a black box within research on psychopathology and it is time to open it. The authors argue that "the study of persons in the context of normal daily life may provide a powerful and necessary addition to more conventional research strategies in psychopathology" (p. 1533). We already have mentioned the importance of minor stress events in the onset of psychosis, and Kimhy, Delespaul, Ahn et al. (2010) point the absence of research investigating this relation in situ:

Given that psychosis, stress, and arousal are variable phenomena that can fluctuate considerably over brief periods of time, the elucidation of their relationships is contingent on the availability of a methodology that allows for the ambulatory, high time resolution simultaneous assessment of the psychological and physiological indices of stress and psychosis during daily functioning. (p. 1133)

With urbanicity identified as of crucial importance in the etiology of psychosis, it becomes evident that such a perspective needs to be implemented in urban contexts. While empirical research on ambiance is very rich and well documented, quite the contrary is the case when we turn to affective atmosphere: "There is a distinct lack of writing on what research methods might be fruitfully employed in attending to atmospheres; it is not obvious how we should go about researching atmospheres [...]" (Adey, Brayer, Masson et al., 2013, p. 302). From that point, the question is "[h]ow can the sphere of empirical social research be re-composed so that it resonates with the concept of affective atmospheres?" (Michels, 2015, p. 258). In order to be able to make a productive proposal to this call, and in coherence with the discussion held above, the central question is less to study what ambiance and affective atmosphere are, and rather focus on what ambiance and atmosphere do (Ash, 2013; Thibaud, 2015).

In recent years, biosensing - an "umbrella term for a variety of different somatic measures" (Osborne \& Jones, 2017, p. 160) - has been advanced as "offering the potential to explore participants' reaction at an embodied level, beyond the subjectivity of self- 
reporting" (p. 160). Among these physiological indicators, electrodermal activity (EDA, also called skin conductance) is considered to be a stable index of the activation of the autonomic nervous system (Subotnik et al., 2012), which is associated with different emotional and cognitive states, as well as attention (Dawson et al., 2000; Critchley, 2005; Belzung, 2007; Boucsein, 2012). Hence, EDA is considered to be a useful and valid index for various psychological processes (Dawson, shell \& Filion, 2000, p. 204; Boucsein, 2012), and has become the most widely used biosignal in the history of psychophysiology (Dawson et al., 2000; Belzung, 2007, p. 30; Boucsein, 2012), as well as in psychology and neuroscience (Belzung, 2007, p. 30). Recently, non-invasive portable EDA monitoring devices have been made commercially available, allowing to collect data in situ. With these recent developments, biosensing methods have gained popularity within social sciences, especially in fields interested in people's experiences, such as mental health research (Cella, Okruszek, Lauwrence et al., 2018), urban studies (Hogertz, 2010) or tourism (Kim \& Fesenmaier, 2015). Together, these studies provide convincing evidence of the usability of these new methods. Osborne and Jones (2017) offer a brief review and reflection on these new methods in geography, and so do Torus and Keshavan (2018) concerning research in mental health. While both identify the powerful potential of these tools, they also identify new challenges for research, be it on practical, analytical or ethical level.

As it has been made clear earlier in this paper, the unconscious and involuntary bodily reactions assessed by biosensing can also be linked to affect, or more precisely to the registration of affect activity in bodies. Hence I suggest here to turn to these physiological measures, in order to produce empirical data in coherence with the conceptual approach suggested by affective atmospheres as discussed in this paper. I am well aware that this is not the only way to propose an empirical application of affective atmosphere, and moreover, I do not claim that this measure is a way to quantify affect in itself, but rather a method to capture how a body is affected by environment, at a level not (yet) registered and mediated by consciousness, as highlighted previously. In other words, it allows to capture the "third realm", the registration of affective activity human bodies mentioned by Ellis, Tucker and Harper (2013). Nevertheless, we have to keep in mind that data collected through monitoring of EDA or other physiological data do not provide emotional states of participants (Dawson, Shell \& Filion, 2000), nor does it take in account contextual factors (Osborne \& Jones, 2017). Hence, it is crucial, in order to obtain fine grained data of how people diagnosed with schizophrenia interact and respond to environment in daily life, to combine this method with qualitative - narrative and observatory - data. Here we may turn to the literature on ambiance, as scholars at CRESSON have been very much involved in developing innovative and adequate methodologies allowing to study ambiances. One of the most well-known tools for assessing how people experience ambiance is the commented city walks (parcours commentés) developed by Thibaud 6 .

The methodological suggestions made here remain at a tentative level and will be further developed in a forthcoming paper dedicated more specifically to the strengths and weaknesses of biosensing research tools, as well as to the way the physiological dataset may be analyzed and integrated with ethnographical data. Nevertheless, it appears that turning to a combination of somatic and qualitative data allows to gain access to an embodied experience of urban environments. When combined with precise locational analysis (through GPS tracking) of the reactions of participants in the urban context, this mixed- method approach allows to obtain fine-grained data of the emotional and stress 
relationship individuals have with the urban environment in daily life situations. This is even more important when we want to capture where and why situations are source of stress.

\section{Conclusion}

Ambiance and affective atmosphere are raised in this paper as a conceptual framework "for examining situated place experience" (Buser, 2014, p. 229), or studying how places feel as Jones and Jam (2015) say. The shared spatial perspective of ambiance and affective atmosphere highlighted in this paper has allowed to identify three research gaps in the study of the entanglement of urbanicity and psychosis, and, moreover, it leads to capture the way people diagnosed with schizophrenia experience cities in situ, which has been showed to be crucial if we seek to better understand the relations between mental illness and the cities we live in.

Furthermore, the article draws out the differences between the concepts of ambiance as conceptualized in French research on architecture and urban sociology on the one side, and affective atmosphere as theorized in recent Anglo-Saxon human geography on the other. The affective dimension refers to an immediate bodily perception, which intervenes even before the consciousness is involved, while ambiance rather points the conscious level of perception of urban environment. This distinction opens the way to the study of how the urban environment is perceived by the senses and mediated by conscious reflection upon it, as well as how this environment is experienced by the bodies, upstream of cognition.

And finally, in suggesting biosensing methods as adequate for the study of the prereflective domain of experience pointed out by the notion of affective atmosphere - and not for measuring affect itself - the article suggests a possibility to reconcile theoretical considerations with empirical outlooks. Moreover, it has been argued that the theoretical couple of ambiance and affective atmosphere provide fertile conceptual ground from which to capture embodied urban experience of people diagnosed with schizophrenia, and therefore contributes to a finer understanding of the city-psychosis nexus.

I would like to thank Ola Söderström for the thoughtful discussions and insights that allowed to tighten the paper. Many thanks also to the anonymous reviewers for their helpful critique and comments on the first draft of the paper.

\section{BIBLIOGRAPHY}

Abbott, Alison. 2012. Urban decay. Nature. vol. 490, p. 162.

Adey, Peter; Brayer, Laure; Masson, Damien; Murphy, Patrick; Simpson, Paul \& Tixier, Nicolas. 2013. "Pour votre tranquillité" : ambiance, atmosphere, and surveillance. Geoforum. vol. 49, p. 299-309. 
Allardyce, Judith; Boydell, Jane; Van Os, Jim; Morrison, Gary; Castle, David; Murray, Robin M. \& McCreadie, Robin G. 2001. Comparison of the incidence of schizophrenia in rural Dumfries and Galloway and urban Camberwell. The British journal of psychiatry: the journal of mental science. vol. 179, p. 335.

Amphoux, Pascal. 2003. Ambiances urbaines et espaces publics. In G. Capron \& N. Haschar-Noé (Eds.), L'espace public en question : usages, ambiances et participation citoyenne. Toulouse : Université Toulouse Le Mirail, p. 50-55.

Anderson, Ben. 2009. Affective atmospheres. Emotion, Space and Society. vol. 2, n 2, p. 77-81.

Ash, James. 2013. Rethinking affective atmospheres: Technology, perturbation and space times of the non-human. Geoforum. vol. 49, p. 20-28.

Augoyard, Jean-François \& Torgue, Henry. 1995. À l'écoute de l'environnement : répertoire des effets sonores. Marseille : Editions Parenthèses.

Belzung, Catherine. 2007. Biologie des émotions. Bruxelles : De Boeck.

Bille, Mikkel; Bjerregaard, Peter \& Sørensen, Tim F. 2015. Staging atmospheres: Materiality, culture, and the texture of the in-between. Emotion, Space and Society. vol. 15, p. 31-38.

Bissell, David. 2010. Passenger Mobilities: Affective Atmospheres and the Sociality of Public Transport. Environment and Planning D: Society and Space. vol. 28, n 2, p. 270-289.

Böhme, Gernot. 1993. Atmosphere as the Fundamental Concept of a New Aesthetics. Thesis Eleven. vol. $36, \mathrm{n}^{\circ} 1$, p. 113-126.

Boucsein, Wolfram. 2012. Electrodermal activity. 2nd ed. New York: Springer.

Brennan, Teresa. 2004. The transmission of affect. Ithaca, NY: Cornell University Press.

Bunney Jr, William E.; Hetrick, William P.; Bunney, Blynn G.; Patterson, Julie V.; Jin, Yi; Potkin, Steven G. \& Sandman, Curt A. 1999. Structured interview for assessing perceptual anomalies (SIAPA). Schizophrenia Bulletin. vol. 25, n 3, p. 577-592.

Buser, Michael. 2014. Thinking through non-representational and affective atmospheres in planning theory and practice. Planning Theory. vol. 13, n 3, p. 227-243.

Candau, Joël. 2010. Intersensorialité humaine et cognition sociale. Communications. $n^{\circ}$ 1, p. 25-36. Cella, Matteo; Okruszek, Łukasz; Lawrence, Megan; Zarlanga, Valerio \& Wykes, Til. 2018. Using wearable technology to detect the autonomic signature of illness severity in schizophrenia. Schizophrenia research. vol. 195, p. 537-542.

Chadoin, Olivier. 2010. La notion d'ambiance. Contribution à l'examen d'une invention intellectuelle postmoderne dans le monde de la recherche architecturale et urbaine. Les annales de la recherche urbaine. vol. 106, $\mathrm{n}^{\circ} 1$, p. 153-159.

Chaperot, Chirstophe \& Altobelli, Adrien. 2014. Psychiatrie et ambiance. L'Évolution Psychiatrique. vol. 79, n³, p. 541-555.

Dawson, Michael E.; Schell, Anne M. \& Filion, Diane L. 2000. The electrodermal system. In C. J. T, T. L. G, \& B. G. G (Eds.), Handbook of psychophysiology, 2nd ed. New York: Cambridge University Press, p. 200-223.

Duff, Cameron. 2015. Atmospheres of recovery: Assemblages of health. Environment and Planning A. vol. $48, \mathrm{n}^{\circ} 1$, p. 58-74.

Ellis, Darren; Tucker, Ian \& Harper, David. 2013. The affective atmospheres of surveillance. Theory \& Psychology. vol. 23, $n^{\circ}$ 6, p. 716-731. 
Faris, Robert E. Lee \& Dunham, Henry Warren. 1939. Mental disorders in urban areas: an ecological study of schizophrenia and other psychoses. Chicago: the University Press of Chicago. Gregg, Melissa \& Seigworth, Gregory J. (Eds.). 2010. The affect theory reader. Duke University Press. Golembiewski, Jan. 2017. Architecture, the urban environment and severe psychosis. Part I: Aetiology. Journal of Urban Design and Mental Health [Online]. vol. 2, $\mathrm{n}^{\circ} 1$, retrieved from https:// www.urbandesignmentalhealth.com/journal.html (consulted on the $22^{\text {nd }}$ of march 2017).

Hasse, Jürgen. 2012. Atmosphären der Stadt: aufgespürte Räume. Jovis Verlag.

Jones, Phil \& Jam, Chris. 2016. Creating ambiances, co-constructing place: a poetic transect across the city. Area. vol. 48, n 3, p. 317-324.

Leys, Ruth. 2011. The turn to affect: A critique. Critical Inquiry. vol. 37, n 3, p. 434-472.

Leys, Ruth. 2017. The ascent of affect: genealogy and critique. University of Chicago Press.

Kazig, Rainer \& Masson, Damien. 2015. L'ambiance comme concept de la géographie culturelle francophone. Défis et perspectives. Géographie et cultures. n 93-94, p. 215-232.

Kelly, Brendan D; O'Callaghan, Eadbhard; Waddington, John L.; Feeney, Larkin; Browne, Stephen; Scully, Paul J.; Clarke, Mary; Quinn, John F.; McTigue, Orflaith \& Morgan, Maria G.; Kinsella, Anthony \& Larkin, Conal. 2010. Schizophrenia and the city: A review of literature and prospective study of psychosis and urbanicity in Ireland. Schizophrenia research. vol. 116, n 1, p. 75-89.

Kim, Jeongmi and Fesenmaier, Daniel R. 2015. Measuring emotions in real time: Implications for tourism experience design. Journal of Travel Research. vol. 54, n 4, p. 419-429.

Kimhy, David; Delespaul, Philippe; Ahn, Hongshik; Cai, Shengnan; Shikhman, Marina; Lieberman, Jeffrey A.; Malaspina, Dolores \& Sloan, Richard P. 2010. Concurrent Measurement of "Real-World" Stress and Arousal in Individuals With Psychosis: Assessing the Feasibility and Validity of a Novel Methodology. Schizophrenia Bulletin. vol. 36, n6, p. 1131-1139.

Krabbendam, Lydia \& Van Os, Jim. 2005. Schizophrenia and urbanicity: a major environmental influence-conditional on genetic risk. Schizophrenia Bulletin. vol. 31, n 4, p. 795-799.

Labanyi, Jo. 2010. Doing things: emotion, affect, and materiality. Journal of Spanish Cultural Studies. vol. $11, \mathrm{n}^{\circ} 3-4$, p. 223-233.

Lysaker, Paul \& Lysaker, John. 2008. Schizophrenia and the fate of the self. Oxford: Oxford University Press.

Massumi, Brian. 2002. Parables for the virtual: Movement, affect, sensation. Duke University Press.

McCormack, Derek P. 2008. Engineering affective atmospheres on the moving geographies of the 1897 Andrée expedition. Cultural Geographies. vol. 15, n 4, p. 413-430.

Michels, Christoph. 2015. Researching affective atmospheres. Geogr. Helv. vol. 70, n 4, p. 255-263. Mortensen, Preben Bo. 2000. Urban-Rural Differences in the Risk for Schizophrenia. International Journal of Mental Health. vol. 29, n 3, p. 101-110.

Myin-Germeys, Inez; Peeters, Frenk P.M.L; Havermans, Rob; Nicolson, Nancy; DeVries, Maarten W.; Delespaul, Philippe \& Van Os, Jim. 2003. Emotional reactivity to daily life stress in psychosis and affective disorder: an experience sampling study. Acta Psychiatrica Scandinavica. vol. 107, $\mathrm{n}^{\circ} 2$, p. 124-131.

Myin-Germeys, Inez; Oorschot, Margreet; Collip, Dina; Lataster, Johan; Delespaul, Philippe \& Van Os, Jim. 2009. Experience sampling research in psychopathology: opening the black box of daily life. Psychological medicine. vol. 39, $\mathrm{n}^{\circ}$ 9, p. 1533-1547. 
Nevid, Jeffrey S.; Rathus, Spencer; Greene, Beverly. 2009. Psychopathologie, 7e éd. Paris : Pearson Education France.

Osborne, Tess \& Jones, Phil Ian. 2017. Biosensing and geography: A mixed methods approach. Applied Geography. vol. 87, p. 160-169.

Pile, Steve. 2010. Emotions and affect in recent human geography. Transactions of the Institute of British Geographers. vol. 35, $\mathrm{n}^{\circ}$ 1, p. 5-20.

Söderström, Ola; Empson, Lilith Abrahamyan; Codeluppi, Zoé; Söderström, Dag; Baumann, Philipp S. \& Conus, Philippe. 2016. Unpacking 'the City': An experience-based approach to the role of urban living in psychosis. Health \& Place. vol. 42, p. 104-110.

Subotnik, Kenneth L.; Schell, Anne M.; Chilingar, Mark S.; Dawson, Michal E.; Ventura, Joseph; Kelly, Kimberle A.; Hellemann, G S \& Nuechterlein, K H. 2012. The interaction of electrodermal activity and expressed emotion in predicting symptoms in recent-onset schizophrenia.

Psychophysiology. vol. 49, nº 8, p. 1035-1038.

Thibaud, Jean-Paul. 2002. L'horizon des ambiances urbaines. Communications. vol. 73, $\mathrm{n}^{\circ} 1, \mathrm{p}$. 185-201.

Thibaud, Jean-Paul. 2011a. The sensory fabric of urban ambiances. The Senses and Society. vol. $6, \mathrm{n}^{\circ}$ 2, p. 203-215.

Thibaud, Jean-Paul. 2011b. The three dynamics of urban ambiances. Sites of Sound: Of Architecture and the Earl. vol. 2, p. 43-53.

Thibaud, Jean-Paul. 2012. Petite archéologie de la notion d'ambiance. Communications. $\mathrm{n}^{\circ} 1, \mathrm{p}$. 155-174.

Thibaud, Jean-Paul. 2013. L'énigme des ambiances en partage. In Thibaud, Jean-Paul \& Duarte, Cristiane Rose (Eds.). Ambiances urbaines en partage. Pour une écologie sociale de la ville sensible. Genève : MétisPresses.

Thibaud, Jean-Paul. 2015. The backstage of urban ambiances: When atmospheres pervade everyday experience. Emotion, Space and Society. vol. 15, p. 39-46.

Thibaud, Jean-Paul. 2016. Les puissances de l'ambiance. Proceedings of 3rd International Congress on Ambiances. Septembre 2016. Volos, Greece.

Thibaud, Jean-Paul \& Thomas, Rachel. 2004. L'ambiance comme expression de la vie urbaine. Cosmopolitiques : aimons la ville. $\mathrm{n}^{\circ} 7, \mathrm{p} .102-113$.

Van Os, Jim. 2004. Does the urban environment cause psychosis? The British Journal of Psychiatry. vol. $184, \mathrm{n}^{\circ} 4$, p. 287-288.

Vassos, Evangelos; Pedersen, Carsten B.; Murray, Robin M.; Collier, David A. \& Lewis, Cathryn M. 2012. Meta-analysis of the association of urbanicity with schizophrenia. Schizophrenia Bulletin. vol. $38, \mathrm{n}^{\circ} 6, \mathrm{p} .1118-1123$.

Wetherell, Margaret. 2012. Affect and emotion: A new social science understanding. London: Sage Publications.

Zubin, Joseph \& Spring, Bonnie. 1977. Vulnerability: A new view of schizophrenia. Journal of abnormal psychology. vol. 86, $\mathrm{n}^{\circ}$ 2, p. 103. 


\section{NOTES}

1. For a more thorough review on ambiance in English, see (Thibaud, 2011a) and (Thibaud, 2011b).

2. My translation of the original text: "Que fait l'ambiance? On se demande ici ce que l'ambiance permet de percevoir, de faire, de vivre, de partager. Au niveau de l'expérience, l'ambiance a la capacité de suggérer des mouvements, inciter des comportements, induire des affects, activer la mémoire du corps, renforcer des sociabilités..."

3. For a critical lecture of this conception of affect, see (Wetherell, 2012), chapters 1-3.

4. For a critical lecture of such duality between affect/emotion and between body/mind, see (Leys, 2011) and (Leys, 2017).

5. My translation of the original text: “Ce moment du sentir constitutif de l'expérience esthétique renvoie plutôt à des façons d'éprouver le monde, se rapporte à des tonalités affectives et des manières d'être ensemble dans un milieu. Avec une telle esthétique des ambiances, on a affaire à la dimension préréflexive de l'expérience, celle qui passe avant tout par un vécu corporel et une sensation immédiate."

6. For a presentation of this method in English, see (Thibaud, 2013).

\section{ABSTRACTS}

The aim of this paper is to ground an analysis of the city-psychosis nexus, and more precisely of the urban experience of individuals diagnosed with schizophrenia in a theoretical framework built on the notion of affective atmosphere, as conceptualized in recent Anglo-American human geography and on the notion of ambiance, as conceptualized in research on architecture and urban studies in France. Drawing upon the confrontation of those concepts, the paper highlights the similarities of ambiance and affective atmospheres, before underlining their differences. It is argued that an atmospheric approach points out dimensions not sufficiently taken into account in research in psychopathology. Furthermore, the two concepts stress two different registers of experience: whereas ambiance puts emphasis on a perceptual, sensory and conscious level of experience of urban environment, affective atmosphere highlights a more pre-reflective, bodily dimension. Finally, the paper sketches out a methodological framework in coherence with this conceptual distinction.

L'objectif de cet article est de fonder une analyse du lien ville-psychose, et plus précisément de l'expérience urbaine des individus diagnostiqués schizophrènes dans un cadre théorique reposant sur la notion d'atmosphère affective, telle que conceptualisée en géographie humaine anglo-saxonne d'une part, et la notion d'ambiance, telle que développée dans la recherche sur l'architecture et l'environnement urbain en France d'autre part. S'appuyant sur la confrontation de ces concepts, l'article discute des similitudes entre ambiances et atmosphères affectives, avant de souligner leurs différences. Il est mis en évidence qu'une approche atmosphérique permet de dégager des dimensions insuffisamment prises en compte dans les recherches en psychiatrie. En outre, ces deux concepts mettent l'accent sur deux registres différents de l'expérience : alors que l'ambiance tend à souligner la dimension sensorielle et consciente de l'expérience, la notion 
d'atmosphère affective met l'accent sur une dimension pré-cognitive et corporelle de cette expérience. Cet article propose ainsi d'esquisser une approche méthodologique en cohérence avec cette distinction théorique.

INDEX

Mots-clés: ambiance, atmosphère affective, schizophrénie, ville, stress, capteurs physiologiques Keywords: ambiance, affective atmosphere, schizophrenia, urbanicity, stress, biosensing

\section{AUTHOR}

\section{MARC WINZ}

Marc Winz is a PhD student, Institute of Geography, University of Neuchâtel, Espace LouisAgassiz, 2000 Neuchâtel, Switzerland marc.winz@unine.ch 